\title{
NGENIEROS MILITARES Y OBRAS PÚBLICAS. ALGUNOS EJEMPLOS DE NUEVA GRANADA EN EL SIGLO XVIII
}

\author{
MANUEL GÁMEZ CASADO
}

Departamento de Historia del Arte. Universidad de Sevilla mgamez@us.es

Resumen: El presente artículo tiene como objetivo analizar el grado de intervención de los ingenieros militares españoles en los principales edificios públicos del virreinato de la Nueva Granada. Para ello se aportarán, además de datos documentales y planos inéditos, nuevas interpretaciones que demuestran el conocimiento por parte de dichos profesionales de la práctica arquitectónica, trasladando a América modelos y tipologías de raíz europea.

Palabras claves: Transferencia cultural / Obras Públicas / Ingenieros Militares / Nueva Granada / Siglo XVIII.

\section{MILITARY ENGINEERS AND PUBLIC WORKS. SOME EXAMPLES OF NEW GRANADA IN 18TH CENTURY}

Abstract: The aim of this article is to analyze the intervention degree of the Spanish military engineers on the main public buildings in the viceroyalty of New Granada. Besides documentary datum and unpublished blueprints, there will be bring out new interpretations, proving the military engineer's knowledge on architecture, bringing to America models and typologies of European roots.

Key words: cultural Exchange / public Works / military engineers / New Granada / Eighteenth century.

\section{Introducción ${ }^{1}$}

Siempre que se ha descrito y comentado la producción de los ingenieros militares españoles en el virreinato de la Nueva Granada durante el siglo XVIII se ha elogiado la ingente labor defensiva que desarrollaron, considerándose, a la vista de la misma, como la época dorada de la poliorcética americana. Es difícil precisar si alguno de los sistemas defensivos de las ciudades neogranadinas fue el de mayor eficacia de cuantos la Corona española levantó en América, pues otros enclaves alejados de dicha zo- na, como La Habana o Veracruz, también contaron con imponentes murallas, baluartes y castillos que protegieron las entradas a sus bahías o puertos. ${ }^{2}$ Con independencia de ello, lo cierto es que en el territorio meridional del Caribe se acumuló el mayor número de plazas españolas fortificadas, como demuestran los casos de Portobelo, Cartagena de Indias, Puerto Cabello, Maracaibo o Santa Marta. ${ }^{3}$ Sobre ellas, hay decenas de estudios que han documentado tanto la historia de esas construcciones, como la labor desarrollada por los ingenieros en los distintos contextos sociales, políticos o cultura-

\footnotetext{
* Fecha de recepción: 15 de octubre de 2017 / Fecha de aceptación: 7 de mayo de 2018.

1 El presente trabajo se inscribe en el desarrollo del proyecto de investigación I+D "Ingenieros militares en el Caribe y el Golfo de México durante el siglo XVIII. Diálogo cultural, circulación trasnacional y conflictos globales HAR2015-63805-P", financiado por el Ministerio de Economía y Competitividad del Gobierno de España.

2 Una visión global del conjunto de fortificaciones construidas en América ofrecen AA.VV., 1985; GUTIÉRREZ, Ramón y ESTERAS, Cristina, 1991; de los mismos autores, 1993; AA.VV., 1996; CALDERÓN QUIJANO, José Antonio, 1996; SERRANO ÁLVAREZ, José Manuel 2003 y GUTIÉRREZ, Ramón, 2005.

3 Las ciudades mencionadas son, de entre las fundadas en Nueva Granada, las que cuentan con un mayor número de edificios destinados a la defensa. Sobre estas construcciones se han escrito diversas monografías, pudiéndose consultar al respecto las realizadas por ZAPATERO, Juan Manuel, 1977; del mismo autor, 1979 y 1980. Igualmente, consúltese LÓPEZ RIVERO, Raúl, 1968 y CASTILLERO CALVO, Alfredo, 2017a.
} 
les americanos. ${ }^{4}$ Sin embargo, da la impresión de no haberse valorado lo suficiente otras aportaciones que contribuyeron al desarrollo urbano de las principales capitales neogranadinas durante el Setecientos. Es el caso de los abundantes ejemplos de puertos, almacenes, puentes, hospitales o aduanas construidas por estos militares en paralelo al diseño de las fortificaciones. ${ }^{5}$

La amplia nómina de proyectos y reformas llevadas a cabo en las ciudades neogranadinas durante el siglo XVIII fue consecuencia de una serie de hechos que alteraron el devenir político hispano. Bien conocido es como con la instauración del tercero de los virreinato indianos, la Corona pretendía solucionar el declive administrativo sufrido en las audiencias de Panamá y Santa Fe, asignándosele a esta última la nueva capitalidad. ${ }^{6}$ No obstante, revocada esta fundación en 1723 a causa del alto costo que suponía para las arcas estatales, no fue hasta 1739 cuando definitivamente se constituyó el nuevo virreinato como respuesta a los ataques sufridos en el istmo por el vicealmirante inglés Edward Vernon. ${ }^{7}$ Con estas nuevas medidas políticas, la Corona pretendía contrarrestar una articulación militar poco efectiva que facilitaba los ataques perpetrados por los enemigos europeos en las principales capitales del Caribe sur, deteniendo el crecimiento económico y amenazando el control del paso.

Dentro de este contexto, los ingenieros militares alcanzaron un papel decisivo en la nueva administración, al ocuparse no solo de la gestión del territorio y de su defensa, sino también de otras construcciones que debían facilitar los distintos aspectos de la vida cotidiana en las Indias. Se trata de un capítulo profesional menos conocido por haberse supeditado la historiografía al estudio de las fortificaciones. Así, el presente texto pretende analizar la función desempeñada por los ingenieros militares en el diseño y construcción de edifi- cios civiles en las principales capitales del litoral caribeño de Nueva Granada, continuando una línea de investigación consolidada por anteriores aportaciones. ${ }^{8}$ Ello permitirá demostrar cómo dichos profesionales implantaron modelos constructivos propios, revalorizando su labor ante algunas voces que ignoraron sus producciones civiles. Su estudio permitirá comprobar si existe un grado de integración de las experiencias edilicias americanas en el contexto de las europeas, pues más allá de la raíz española de los modelos utilizados, se podrán rastrear en algunos de los ejemplos analizados otras corrientes arquitectónicas, como la italiana o la francesa. En otras ocasiones, la adaptación de estos patrones a una realidad geográfica distinta, convertía a los edificios públicos americanos en creaciones novedosas, alejados de cualquier parangón y poseedores de una originalidad inaudita en Europa. Ello hacía a los ingenieros militares protagonistas del proceso de transferencia cultural entre el ámbito europeo y el americano, al trasladar al nuevo continente no solo tipologías, órdenes y normas constructivas, sino también ideas, modelos de tratados y otras fuentes que enriquecieron el desarrollo artístico de los distintos virreinatos. Por ello, el presente estudio prescinde de la aportación de nuevos proyectos de obras públicas. De hecho, más allá del estudio de planos y expedientes hasta ahora inéditos, se pretende sistematizar las distintas construcciones en base a una serie de criterios comunes que denotarán una cierta unidad arquitectónica en el ámbito neogranadino por parte de los ingenieros españoles.

\section{De ingeniero militar a arquitecto público: la fundación del Real Cuerpo y su rama civil}

Dentro de los numerosos calificativos con los que la historiografía se ha referido al papel de los ingenieros militares españoles, probablemente sea el de su carácter polifacético el que mejor defina

${ }^{4}$ Un compendio de tales aportaciones es la monografía publicada por CRUZ FREIRE, Pedro; LÓPEZ HERNÁNDEZ, Ignacio J., 2017.

${ }^{5}$ LAORDEN RAMOS, Carlos, 2012, pp. 137-154. Otros estudios han analizado las obras civiles construidas por los ingenieros en la Península Ibérica, caso de los realizados por AGUILAR CIVERA, Inmaculada, 2008; de la misma autora, 2012; CANTERA MONTENEGRO, Jesús, 2012, pp. 13-32; AGUILAR CIVERA, Inmaculada y DOMÉNECH GARCÍA, Sergi, 2014 y CRESPO DELGADO, Daniel, 2017. Igualmente, las construcciones públicas realizadas en la isla de Cuba durante el siglo XIX han sido estudiadas por LÓPEZ HERNÁNDEZ, Ignacio J., 2016, pp. 483-508. En este sentido, resulta de interés destacar las publicaciones relativas a las obras públicas e infraestructuras promulgadas por el CEHOPU, destacando la edición de tratados de arquitectura y construcción de puentes, de documentos históricos relacionados con la materia y de la Revista de Obras Públicas.

${ }^{6}$ NAVARRO GARCíA, Luis, 1975, pp. 95-97.

7 SERRANO ÁLVAREZ, José Manuel, 2006, pp. 359-383.

${ }^{8}$ El principal estudio que documentó algunos proyectos de obras públicas dirigidos por ingenieros militares en Nueva Granada y abrió diversas líneas de atribución se debe a LAORDEN RAMOS, Carlos, 2008. Igualmente, consúltese GONZÁLEZ TASCÓN, Ignacio, 1992. 
sus producciones. Así, fueron numerosos los que durante los siglos XVI y XVII compaginaron el diseño de las fortificaciones con la construcción de máquinas, edificios públicos e infraestructuras, denotando una relevante versatilidad en sus labores. El hecho de que el término "ingeniero" se asocie únicamente al arte de la guerra responde a un convencionalismo, generado a partir de la falta de conocimiento del resto de obras. Al respecto, cabe citar al ingeniero sienés Tiburcio Spannocchi, quien realizó fortificaciones para las ciudades de Jaca, Pamplona o Fuenterrabía, en las cuales incluyó edificios destinados al servicio y a la administración. ${ }^{9}$ Igualmente, a Juanelo Turriano, natural de Cremona, se le debe el más ingenioso artificio hidráulico de cuantos se construyeron en la Península, pues elevaba el agua desde el río Tajo hasta la meseta toledana. ${ }^{10}$ Por otro lado, Cristóbal de Rojas, singular ingeniero y excepcional tratadista, no solo trabajó en las fortificaciones de Cádiz, sino que también lo hizo en la Iglesia del Sagrario de Sevilla o en el convento de Santo Domingo de Sanlúcar de Barrameda, donde ya se ha destacado el uso de estampas y modelos italianizantes en la traza de su portada. ${ }^{11}$

No obstante lo comentado, la situación institucional de los ingenieros militares varió durante el siglo XVIII. Promulgado en abril de 1711 el conocido Plan General de los Ingenieros de los Ejércitos y Plazas por el rey Felipe V, se constituyó el Real Cuerpo de Ingenieros españoles, institucionalizándose la profesión y otorgándosele un carácter reglado hasta entonces inexistente. Las bases del nuevo organismo partían de las propuestas del ingeniero Jorge Próspero Verboom, formado en la Academia de Matemáticas de Bruselas y hombre de confianza del monarca. Sin embargo, no fue hasta julio de 1718, una vez concluida la Guerra de Sucesión, cuando se proclamó la primera ordenanza que reguló tanto las funciones de los ingenieros en los empleos públicos, como el papel de estos en la defensa y organización del territorio.
Esta categoría les exigía informar periódicamente sobre el estado de las ciudades, caminos, puentes y ríos. ${ }^{12}$ Igualmente, a través de la citada ordenanza, el gobierno iniciaba una política de inversión en obras públicas, recayendo en los ingenieros militares la función de construir las infraestructuras necesarias al no existir, como si ocurría en Francia, un cuerpo especializado en tales menesteres. ${ }^{13}$

Con la llegada al trono de Carlos III y la irrupción de las teorías ilustradas entre los círculos intelectuales españoles se impulsó la construcción de obras públicas, coincidiendo con la mejor generación de ingenieros militares. ${ }^{14}$ La apuesta por modernizar las infraestructuras de las ciudades era consecuencia de una nueva política económica que entendía la necesidad de mejorar las comunicaciones, lo que estimularía el comercio y las riquezas de la Corona. ${ }^{15}$ Con esta nueva mentalidad, la producción ingenieril se concibió como muestra del poder financiero del reino, integrándose en el propio paisaje y mostrándose incluso en numerosas pinturas junto a los más destacados puertos, ríos y fondeaderos. ${ }^{16}$ Esta circunstancia requería de una mayor organización de los ingenieros, por lo que en 1774 se dividió el Cuerpo en tres ramos encabezados por un director. En el napolitano Francisco Sabatini recayó la máxima autoridad de la sección dedicada a Caminos, Puentes, Edificios de Arquitectura Civil y Canales de Riego. ${ }^{17}$ Con esta disposición se iniciaba una segregación de arquitectos, ingenieros civiles e ingenieros militares, apoyada por la fundación de la Academia de Nobles Artes de San Fernando, la cual, basándose en el modelo ilustrado francés, dispuso un control sobre el gusto en detrimento de las habilidades técnicas. Asimismo, al conde de Floridablanca se le debe la creación en 1779 de la Academia de Ciencias, fomentando el estudio de lo empírico y experimental. Nueve años después se creaba el Gabinete de Máquinas de Madrid, considerado el primer centro científico oficial, cuyo primer director, Agustín de Betancourt, fue nombrado Inspector General de Caminos. Todo ello permi-

\footnotetext{
9 CÁMARA MUÑOZ, Alicia, 1988, pp. 77-90.

10 CRESPO DELGADO, Daniel, 2014, pp. 9-23.

11 MORALES, Alfredo J., 1982, pp. 17-20 y LUENGO GUTIÉRREZ, Pedro, 2018, pp. 113-126.

12 CAPEL, Horacio; SÁNCHEZ, Joan Eugeni; MONCADA, Omar, 1988, pp. 25-35.

${ }^{13}$ En 1712 se fundó en Francia el Cuerpo de ingenieros de Ponst et Chaussées, especializados en la construcción de caminos, puentes y puertos, eximiendo a los destinados al diseño de fortificaciones de cualquier tarea relacionada con las obras públicas. Para conocer su reglamento, véase DEBAUVE, Alphonse, 1871.

${ }^{14}$ MORALES, Alfredo J., 2016, pp. 67-78.

15 SAMBRICIO, Carlos, 1986.

${ }^{16}$ Dichas representaciones han sido estudiadas por CRESPO DELGADO, Daniel, 2015, pp. 35-48.

17 CAPEL, Horacio; SÁNCHEZ, Joan Eugeni; MONCADA, Omar, 1988, pp. 78-79.
} 
tió fundar en 1799 el Cuerpo de Ingenieros de Caminos y Canales, clausurado pocos años después a causa de la invasión francesa, pero que sirvió de base para el fomento de la formación civil de los arquitectos e ingenieros que trabajaron durante el siglo XIX. Estas fundaciones valieron para separar definitivamente las labores arquitectónicas e ingenieriles, iniciando un debate, bien estudiado por Bonet, en el que los arquitectos no solo reclamaban haber sido desposeídos de sus intereses económicos, sino también haber perdido el elevado estatus social que en tiempos habían tenido. ${ }^{18}$

El contexto institucional descrito repercutía de forma particular en el caso americano. La escasez de ingenieros desplazados a América imposibilitaba ejecutar las nuevas políticas constructivas borbónicas, pues tan alto número de transformaciones urbanas era inabarcable para los allí destinados. Además, sus actuaciones estuvieron condicionadas por los continuos conflictos bélicos acaecidos durante el siglo XVIII en el ámbito caribeño, por lo que centraron sus esfuerzos en la terminación de un plan de defensa que relegaba a un segundo plano las construcciones civiles. No obstante, lo excepcional de la producción pública de los ingenieros militares en Nueva Granada supera lo sucedido en otros contextos, pues estos suplieron la falta de arquitectos y maestros de obras que construyesen edificios destinados a la administración política y económica que requería el nuevo virreinato. De entre ellos, ingenieros como Juan de Herrera y Sotomayor, Ignacio Sala, Manuel Hernández o Antonio de Arévalo destacaron en la proyección, diseño y traza de estos inmuebles, alcanzando un desarrollo arquitectónico equiparable con lo acaecido en la realidad europea.

\section{Ingenieros militares y obras públicas en Nueva Granada. Nuevas aportaciones}

Una vez contextualizado el papel de los ingenieros militares españoles en lo concerniente al diseño de edificios públicos, se plantean a continuación algunas de sus intervenciones en los puentes, edificios gubernamentales y aduanas de Nueva Granada. En su desarrollo se comprobará cómo dichos militares cumplieron con las exigencias edili- cias del nuevo virreinato, pues además de construir algunas de las más eficaces fortificaciones americanas, también se ocuparon de embellecer las principales capitales del Caribe sur.

\section{Fundación de ciudades e intervenciones urbanísticas}

El proceso de control territorial del virreinato neogranadino requería de una serie de fundaciones urbanas que ocupasen tan vasto territorio, y así contrarrestar la presencia de tribus indígenas que rechazaban el dominio español. Las nuevas políticas borbónicas impuestas durante el siglo XVIII, primordialmente durante el reinado de Carlos III, pretendían acabar con tal problema, pues las relaciones con los nativos no eran positivas en Tierra Firme desde los primeros años de la conquista. ${ }^{19}$ Esta situación se agravó especialmente en dos regiones fronterizas entre distintas audiencias, pobladas por belicosos indios liderados por poderosos caciques y resistentes a abandonar el control de sus pueblos. La primera de ella es el Darién, actual frontera entre Colombia y Panamá y considerado un enclave estratégico para la comunicación de los puertos de Cartagena de Indias y Portobelo. Allí, los Cunas establecieron un comercio ilegal con los ingleses provenientes de Jamaica, reduciendo el control político y territorial de las autoridades virreinales y haciendo peligrar el dominio del istmo. ${ }^{20}$ Por ello, la Corona, además de crear unidades de vigilancia en el golfo darienita como los guardacostas reales, aprobó una serie de expediciones encabezadas por ingenieros militares para fundar nuevas ciudades que mejorasen el control del territorio. ${ }^{21}$

Conocidas algunas de las campañas ejecutadas por el ingeniero Juan de Herrera y Sotomayor en la Nueva Calidonia, fue Antonio de Arévalo el que protagonizó las principales expediciones a la zona. Así, más allá del establecimiento de fuertes efímeros, Arévalo propuso para el Darién en 1785 trazar una serie de fundaciones en los extremos del istmo que convergiesen hacia el interior para controlar a los Cunas y alcanzar el dominio territorial. ${ }^{22}$ El proyecto no fue finalizado, pues la oposición del virrey Caballero y Góngora lo impidió, aunque la creación de algunas de estas poblaciones si frenó la creciente influencia nativa en la zona. ${ }^{23}$

\footnotetext{
18 BONET CORREA, Antonio, 1985, pp. 19-33.

19 KUETHE, Allan; KENNETH, Andrien, 2014, pp. 244-331.

20 Véase FELICIANO RAMOS, Héctor, 1990.

21 GÁMEZ CASADO, Manuel, 2018, pp. 211-236.

22 LUENGO MUÑOZ, Manuel, 1961, pp. 342-343.

${ }^{23}$ CASTILLERO CALVO, Alfredo, 2017b, pp. 323-324.
} 
Diferente fue el caso de La Guajira, donde el propio Arévalo fundó varias poblaciones siguiendo la misma intención que en el caso darienita, esto es, obtener el control de la población indígena a través de su sometimiento. Así, el ingeniero refundó en 1774 la ciudad de San José de Bahía Honda, mientras que en el municipio de Orino se ocupó de reordenar su urbanismo para adaptarlo a las nuevas exigencias, construyendo una iglesia y una plaza mayor que seguía los modelos implantados por la Corona en las capitales americanas. ${ }^{24}$ Por otro lado, en la ciudad de Sabana del Valle, Arévalo no solo proyectó las defensas de la plaza, sino que también se preocupó por rehabilitar su puerto, facilitar el suministro de agua mediante la construcción de una red de cañerías y construir viviendas para el personal de administración y servicio de la ciudad. ${ }^{25}$

Más allá de lo comentado, la labor urbanística de los ingenieros militares en las capitales neogranadinas se redujo a la elaboración de distintos informes reconociendo el estado de sus edificios, murallas y calles. Con estas labores trazaban un plan en el que jerarquizaban las distintas prioridades constructivas. Esto dio como resultado algunos planos, aún conservados, en los que se marcaron los edificios que jalonaban el desarrollo urbano de las ciudades. Así lo hizo Herrera y Sotomayor en Cartagena de Indias, valorando la correcta situación de las construcciones para una posible defensa ante un ataque enemigo. ${ }^{26}$ Por otro lado, tras el bombardeo de Portobelo por Kinghills en 1744 , se envió una comisión, encabezada por el ingeniero Nicolás Rodríguez, para tasar el número de casas incendiadas, evaluando el valor de las propiedades, sus dimensiones, su ubicación, los materiales y el nombre del propietario. Dicho informe se ha estimado como el primer censo hecho en la ciudad, permitiendo reconstruir su urbanismo y demostrando el valor de la documentación generada por los ingenieros militares. Caso similar practicó Ignacio Sala, quien redactó en enero de 1753 una pormenorizada descripción de la bahía y ciudad de Portobelo. Ésta se acompaña por un mapa que da cuenta de todas las construcciones civiles y militares, considerándose la más exhaustiva relación y el mejor testimonio para conocer el estado de la localidad. Además, Sala diferenció en el texto tanto el proceso constructivo de algunos edificios portobeleños, como la Real Contaduría, la iglesia de La Merced o el hospital de San Juan de Dios, como las realidades de los dos barrios principales, Guinea y La Ciénaga, distinguiéndolos asimismo en el plano mencionado. ${ }^{27}$

\section{El palacio de los virreyes de Nueva Granada}

Con la creación del virreinato de la Nueva Granada era necesario establecer una serie de mejoras en el edificio designado para acoger a las nuevas autoridades, la antigua Casa de la Moneda de Santa Fe. Fundada en 1620 por Alonso Turrillo de Yebra, la fábrica no contaría con la riqueza necesaria para albergar al nuevo gobierno virreinal, pues se exigía mostrar una imagen de poder y majestuosidad en el centro de la capital. ${ }^{28}$ Trazadas las modificaciones iniciales durante la primera mitad del siglo XVIII por una serie de arquitectos locales, en febrero de 1763 una pavorosa tormenta derribó parte de las techumbres, compuestas por maderas de mala calidad utilizadas por maestros de obras carentes de experiencia. ${ }^{29}$ Este contratiempo explica que las autoridades acudiesen a los ingenieros militares para la finalización del edificio, pues la formación de éstos garantizaba la correcta transformación del inmueble. Conocido es el plano trazado en 1766 por Aparici en el que muestra una vista general de toda la plaza, incorporando algunas modificaciones al palacio. Éste ocuparía uno de los laterales del zócalo, constituyendo, junto a la Catedral, la plaza central de Santa Fe. Esta disposición, ya apuntada por el ingeniero italiano Francesco di Marchi cuyo tratado, publicado en 1599, era bien conocido por los militares españoles, fue utilizada para la ordenación territorial de las principales ciudades americanas. ${ }^{30}$ De este modo, Aparici no solo se ocupó de la remodelación interna del palacio, pues también lo entendía en relación al conjunto de edificios

\footnotetext{
24 POLO ACUÑA, José, 2001, pp. 213-250.

25 GÁMEZ CASADO, Manuel, 2016, pp. 373-386.

26 MARCO DORTA, Enrique, 1988, FIG. 71.

27 CASTILLERO CALVO, Alfredo, 2017a, pp. 558-563 y 582-583.

28 Véase PÉREZ SINDREU, Francisco de Paula, 1995, pp. 143-156.

${ }^{29}$ Archivo General de la Nación Colombiana (en adelante AGNC). "Informe Casa de la Moneda amenaza ruina el edificio". 1763. MISCELANEA: SC.39, 129, D.15.

30 Se conocen dos copias del tratado, conservándose la consultada en la Biblioteca Nacional de España. MARCHI, Francesco, 1603, cap. XXVIII.
} 


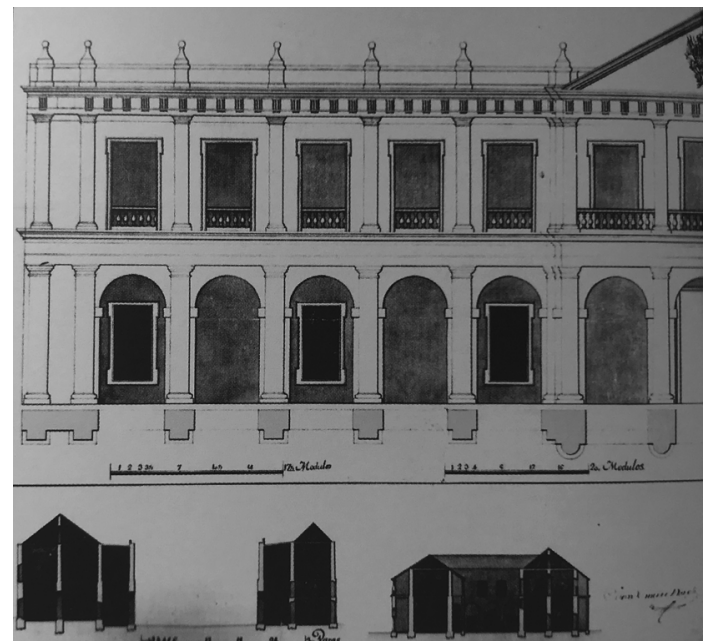

Fig. 1. Juan Ximénez Donoso. Fachada del palacio virreinal de Santa Fe. 1775. Cartoteca del Archivo General Militar de Madrid. COL-10/8.

que lo rodeaban. En este sentido, pretendía trazar un complejo homogéneo que sirviese como centro político, partiendo para ello de las propuestas urbanísticas italianas.

No obstante, el proyecto de reforma definitivo se debe al ingeniero Juan Ximénez Donoso, quien en 1781 trazó desde Cartagena de Indias una serie de planos en los que mostraba el aspecto definitivo del palacio. Donoso propuso articular el inmueble en torno a una serie de patios, integrando en sus crujías un cuartel, la cárcel, las caballerizas y las estancias dedicadas al gobierno. Además, entre estos planos, se encontraba un modelo de fachada de corte académico dividida en dos cuerpos apilastrados, formándose el inferior por una sucesión de arcos, mientras que el superior destaca por su carácter adintelado. Al centro, un imponente frontón triangular que albergaba el escudo de armas de Carlos III animaba una portada sin ornamentación, ni elementos decorativos destacados. El nuevo proyecto coincidía con las propuestas que otros ingenieros militares estaban desarrollando en distintos contextos, pues la articulación de la fachada se asemeja con lo esbozado también en 1781 por Nicolás Lafora para las Casas Reales de Oaxaca en México o, de forma más modesta, con la casa del Gobernador en Santiago de Cuba.

Sin embargo, el proyecto de Ximénez Donoso nunca se ejecutó, pues en 1786 , tras el terremoto del año anterior, el virrey José Manuel de Ezpeleta le encargó al ingeniero Domingo Esquiaqui una nueva propuesta que contase con la aprobación de la Real Academia de Bellas Artes de San Fernando de Madrid. ${ }^{31}$ Pero dichas modificaciones tampoco se llevaron a cabo, coincidiendo el aspecto actual del edificio con las reformas que durante el siglo XIX se realizaron tras distintos derrumbes provocados por seísmos. Lo cierto es que los ingenieros militares intervinieron en el palacio adaptándolo a los intereses funcionales generados por la nueva administración, albergando espacios para los distintos fines administrativos aunque sin relegar la necesidad de mostrar la imagen del poder del nuevo virreinato.

\section{Aduanas}

Con la creación del virreinato neogranadino se incrementó la necesidad de establecer un control sobre el comercio para evitar la proliferación del contrabando existente entre los nativos y los enemigos europeos instalados en el Caribe. Realmente no se ha considerado que existiese una tipología definida para la construcción de aduanas, obedeciendo cada una de ellas a modelos y diseños distintos. Diferente es que contasen con estancias similares en función de su uso, pues la mayor parte de ellas se articularon en dos pisos en torno a un patio central, dedicándose el primero a las oficinas y almacenes, mientras que en el segundo habitaba el Oficial Real.

Con anterioridad a la fundación de Portobelo, esto es, cuando en 1596 la ciudad se encontraba aún proyectándose, la Real Hacienda ya aceptó la construcción de su Aduana por el ingeniero Bautista Antonelli, edificio que diseñó con una sola planta. Ello lo hacía insuficiente para atender al tráfico de comerciantes que arribaban a la ciudad durante las ferias, por lo que durante el siglo XVII se sucedieron una serie de proyectos, algunos debidos a ingenieros militares, que pretendían solucionar la falta de espacio en la fábrica. Además, tras el citado bombardeo de Kinghills el edificio quedó en ruinas, recayendo en el ingeniero Manuel Hernández la rehabilitación y modernización del mismo en 1751. A pesar de no contar con ningún plano que muestre visualmente lo propuesto por Hernández, la extensa documentación generada permite conocer su labor. En primer lugar, el ingeniero eliminó los techos y los suelos preexistentes, así como las columnas que soportaban las arcadas de la fachada. Desmantelado todo el edificio, Her-

31 ARBAIZA BLANCO-SOLER, Silvia, 2010, p. 90. 
nández podía ejecutar su proyecto sin necesidad de adaptarse a la distribución original, que impedía aplicar sus nuevas propuestas. Para un profesional de su formación era más acertado diseñar un proyecto de nueva planta que adaptarse a uno anterior, máxime tras haberse probado la falta de utilidad de su fábrica en un periodo donde aún estaban vigentes las ferias de galeones. Precisamente para mejorar el tránsito de personas, el ingeniero propuso en 1760 la realización de dos pasillos abovedados situados en los extremos de la edificación, pues uno serviría de entrada y el otro de salida a imitación de los vistos por Hernández en las Aduanas de Barcelona y Cádiz. Es más, el ingeniero calificó como necesaria la construcción de estos pasajes, ya que impedirían la acumulación de comerciantes en el acceso al recinto, denotando una preocupación por la funcionalidad del edificio propia de un militar de su formación. Esta característica se acrecentó al proponer la utilización de uno de los pasillos como almacén en la época en que no hubiese ferias, un uso que se mantuvo hasta la independencia de Panamá. ${ }^{32}$

Ciertamente, Manuel Hernández se encontró un inmueble en ruinas, pues las modificaciones acometidas durante el siglo XVII no tuvieron los resultados esperados. Tras su intervención resultó una fábrica de planta rectangular, carente de patio central, a diferencia de otras Aduana como la de México o Campeche, de dos plantas y situada en paralelo a la bahía, a donde se abre una de sus fachadas mayores. ${ }^{33}$ Éstas se forman por dos cuerpos, diferenciados por una cornisa saliente, configurándose el inferior por una elegante sucesión de arcos de medio punto sobre columnas, mientras que en el superior se abren unas ventanas rectangulares. En la calle central los soportes se convierten en gruesos pilares, marcando el centro del edificio, que carece de portada. Esta desornamentación de la Aduana portobeleña muestra el interés de Hernández por la estética academicista aprendida durante su formación en la Academia de Matemáticas de Barcelona. El hecho de que el proyecto tuviese que ser aceptado por la Corte obligaba a adaptarlo a los cánones estéticos exigidos, pretendiéndose, con la renuncia a lo decorativo, ofrecer una imagen de racionalidad, fuerza y

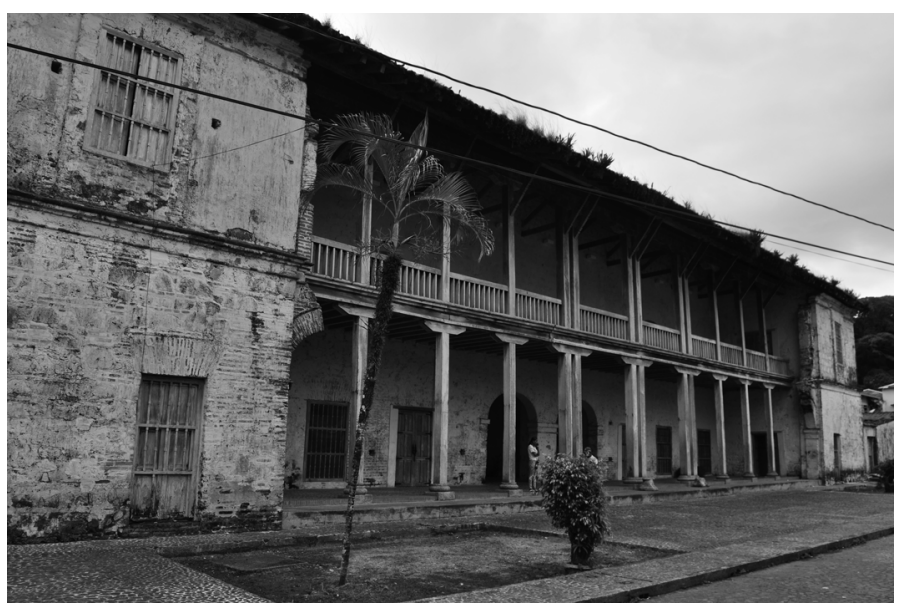

Fig. 2. Manuel Hernández. Aduana de Portobelo. 17511760. Foto: autor.

poder acordes con las nuevas políticas borbónicas en las Indias.

Similar caso ocurrió con la Aduana de la ciudad venezolana de Cumaná, cuya construcción fue solicitada por el gobernador José de Urrutia en 1766 al no existir un edificio destinado al comercio. ${ }^{34} \mathrm{El}$ proyecto fue realizado por el ingeniero Juan Antonio Perelló, quien trazó un plano del edificio en octubre de 1770 y lo presupuestó doblando los 3.000 pesos acordados con la Corona, conservándose una ingente documentación sobre el proceso en los archivos estatales. ${ }^{35} \mathrm{Al}$ igual que en el caso portobeleño, la Aduana fue construida en la orilla del río con el fin de facilitar la descarga de mercancías, lo que incrementaba la dificultad para la instalación de los cimientos ante el estado arenoso del suelo. El acceso a la fábrica, concebida en un solo piso, se hacía a través de un corredor delantero con parejas de puertas en el frente y en los laterales. Como era frecuente en este tipo de edificios, en torno a un patio se articulaban las distintas estancias, entre las que destacaba un amplio almacén al fondo, sostenido al centro por cuatro pilares rectangulares, ideado para acopiar los productos. En el plano, Perelló incluyó, además de la planta, una sección de todo el edificio, mostrando su ca-

\footnotetext{
32 CASTILLERO CALVO, Alfredo, 2017 a, pp. 634-636.

33 Véase LÓPEZ HERNÁNDEZ, Ignacio J., 2015.

${ }^{34}$ Archivo General de Indias (en adelante AGI). "El oficial real contador de Cumaná da parte de haberse acabado de fabricar la aduana del costo que ha tenido y de haberse puesto en uso". Cumaná, 1 de diciembre de 1776 . Francisco Andrade a José de Gálvez. Signatura Caracas, 908.

${ }^{35}$ AGI. "Plano y perfil de la aduana de Cumaná". Juan Antonio Perelló. 4 de octubre de 1770. Signatura MP-Venezuela,160.
} 


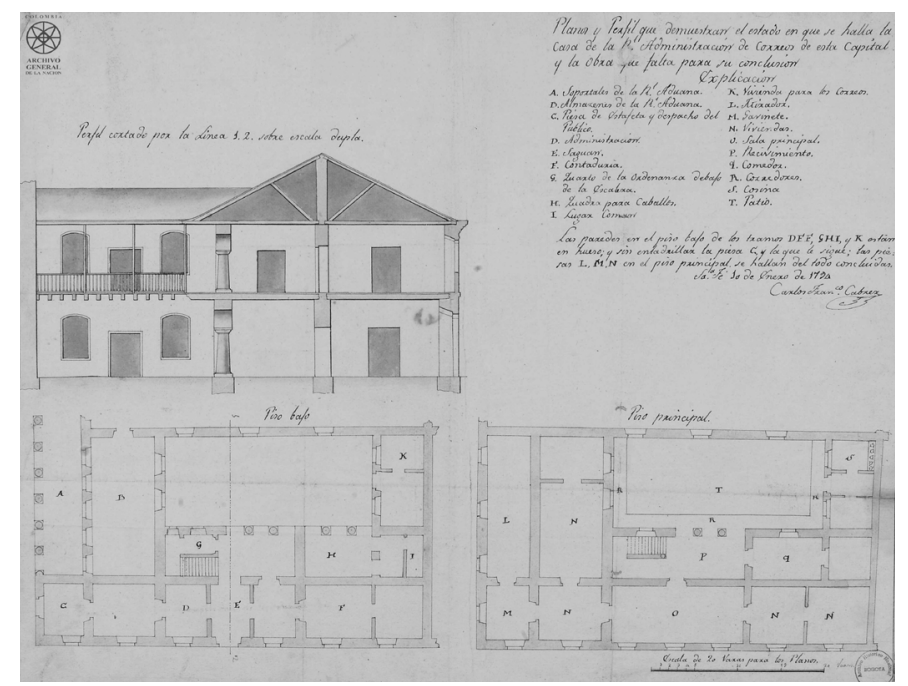

Fig. 3. Carlos Francisco Cabrer. Proyecto para la nueva Casa de Correos de Santa Fe de Bogotá. 1794. Archivo General de la Nación, Colombia. Mapas y Planos, Mapoteca no 4, ref. 35-A.

rácter diáfano, su rigurosa ordenación y el aprovechamiento del espacio interior. No obstante, en 1791 la construcción de la Aduana no había finalizado, pues la gobernación solicitó a los comerciantes el $1 \%$ de los beneficios de sus ventas, medida desestimada por el síndico de la ciudad.

La última de las Aduanas construidas por un ingeniero militar fue la Santa Fe de Bogotá, proyectada por Carlos Francisco Cabrer en 1791, después de que el terremoto acaecido seis años antes arruinase el edificio. ${ }^{36}$ Dirigido el proceso constructivo por el coronel Domingo Esquiaqui, se advirtieron una serie de desperfectos en la fábrica antigua, por lo que fue necesaria su demolición para iniciar la nueva Aduana. Así, en 1792, durante el mandato del virrey José Manuel de Ezpeleta, la Administración principal de Correos de Santa Fe solicitó la construcción de su nueva oficina en la parte alta del edificio destinado a Aduana, circunstancia que obligó a una restructuración presupuestaria del conjunto. Por ello, en enero de
1794, Cabrer entregó un nuevo proyecto al virrey acompañado de un plano explicativo sobre la distribución de cada uno de los pisos, dedicando el bajo a las labores aduaneras y el principal a las oficinas de correos. ${ }^{37}$ Como se muestra en el plano adjunto y ahora reproducido, las distintas dependencias se articulaban en torno a un patio situado en la parte trasera del conjunto, lo que la diferencia de las otras Aduanas. Igualmente, Cabrer equipó el edificio con cocina, comedor, viviendas y un balcón corrido en la planta alta, mejorando las condiciones de habitabilidad de los funcionarios. Esta aduana, considerada la de mayores dimensiones de cuantas se construyeron en la América hispana, es ejemplo de las distintas variantes que los ingenieros militares elaboraban a partir de un mismo modelo. Su labor no solo venía a suplir la falta de arquitectos que dotasen de nuevas infraestructuras a la capital del virreinato, sino que también sirvió para introducir diseños, técnicas y prototipos aprendidos durante su formación académica dentro del proceso de transmisión de modelos al continente americano.

\section{Puentes}

De entre todas las edificaciones aquí tratadas, probablemente sea la construcción de puentes la que tenga un mayor vínculo con respecto a la actual profesión de ingeniero. Resulta evidente que para la correcta articulación de la red de comunicaciones diseñada con el fin de unir las distintas ciudades, el gobierno virreinal aprobó la edificación de distintos puentes que salvarían los numerosos ríos que recorren Tierra Firme. Los construidos responden a diversas tipologías, siendo mayoritarios los que cuentan con un único vano, que pueden ser adintelado o de medio punto. Por otro lado, dependiendo del uso y del punto geográfico de construcción, se idearon con distintos materiales, pues existen algunos proyectados con madera, mientras que otros se hicieron de cantería. ${ }^{38}$ Por otra parte, los ingenieros activos en este periodo intervinieron sobre puentes realizados en etapas anteriores, dentro de la política de rehabilitación de las infraestructuras antiguas promulgada por la Corona durante el siglo XVIII. ${ }^{39}$ Es bien

\footnotetext{
${ }^{36} \mathrm{AGI}$. "El virrey de Santa Fe da cuenta con dos expedientes originales del estado de las obras de almacenes de aduana y casa de correos de esta capital". Santa Fe, 19 de noviembre de 1793. El virrey Espeleta a don Diego de Gardoqui. Signatura Santa $\mathrm{Fe}, 908$.

${ }^{37}$ AGI. "Plano de la Administración de Aduanas y Casa de Correos". 31 de mayo de 1790. Carlos Francisco Cabrer. Signatura MP-Panama, 362.

38 GONZÁLEZ TASCÓN, Ignacio, 1992, pp. 537-549.

39 Precisamente a lo largo del Setecientos se produjo entre los arquitectos españoles un encendido debate sobre las innovaciones técnicas en la construcción de puentes. Al respecto, véase REDONDO CANTERA, María José; ARAMBURU-ZABALA, Miguel Ángel, 1996.
} 
conocido que los ingenieros utilizaban con asiduidad modelos publicados en los principales tratados de arquitectura civil, pues autores como Bélidor recogen varios tipos de puentes que sirvieron de base para las propuestas indianas. ${ }^{40}$ Más especifico resultó el tratado escrito por el ingeniero alemán Christan Schramm, en el que incluyó una amplia variedad de tipologías constructivas relacionadas con los puentes, especificando la utilidad de cada uno y el modo de trazar las distintas piezas que los conformaban. ${ }^{41}$ Todo ello se debe entender en paralelo a los proyectos de los constructores reales, quienes diseñaron diversos puentes que desde 1786 estaban supeditados a la aprobación de la Comisión de Arquitectura, cerciorándose un acercamiento en las tareas constructivas entre arquitectos e ingenieros como consecuencia de una misma especificidad técnica. ${ }^{42}$

Resulta evidente que la erección de puentes obligaba al ingeniero a realizar un ejercicio de cálculo, relegando los aspectos decorativos y asumiendo la necesidad de trazar una construcción meramente funcional. Por ese carácter utilitario, desde fines del siglo XVII se hizo necesario reparar el puente que cruzaba el río Gualí, pues permitiría tanto intensificar las relaciones comerciales entre las provincias de Mariquita e Ibagué, como facilitar el traslado a plazas menores dentro de la Audiencia de Santa Fe, caso de Honda. Así, en 1710 se iniciaron las labores de rehabilitación por el capitán Manuel Piñeros Montenegro, pero la falta de medios económicos como consecuencia de la Guerra de Sucesión impidió finalizar los trabajos. No obstante, coincidiendo con la llegada del ingeniero Ignacio Sala a Cartagena de Indias para ocupar el cargo de gobernador, la Corona le encargó la definitiva reconstrucción del puente. ${ }^{43}$ Tras esta designación, en 1750 realizó una serie de reconocimientos para comprobar su estado, enviándole al virrey José Alfonso Pizarro, Marqués del Villar, una serie de cartas en las que le comunicaba las fallas encontradas en los anteriores proyectos. Tales eran los errores tectónicos que presentaba la construcción, que el propio Sala incluyó en sus informes un plano, ahora reproducido, en el que recogía su proyecto de reforma, asumiendo la responsabilidad exigida por su cargo. ${ }^{44}$ En el plano, fechado en 1750, trazó la planta, una vista lateral y una sección frontal de la pasarela. ${ }^{45} \mathrm{El}$ ingeniero planteó la construcción de un puente de madera, de tablero liso y sobre estribos de cantería. Sostenida gracias a dos caballetes unidos por un punto central, la tablazón se disponía transversal a los cuatro durmientes ensamblados a una viga central. La estructura lígnea apeaba en soportes pétreos, dispuestos en los márgenes del río, dándole distintos usos a los materiales en función de su localización dentro del conjunto. La propuesta, destinada a cubrir una luz no demasiado amplia, resultaba senciIla y correcta tanto por su mecánica, como por su estática, demostrando un conocimiento por parte de Sala de las modernas teorías europeas al respecto, las cuales ya había aplicado en sus proyectos gaditanos. Entre ésas cabe señalar como el tratado de Leupold, publicado en 1726 en Leipzig, ofrece varios dibujos de puentes coincidentes con las ideas del ingeniero español, insistiendo en el perfeccionamiento de la cantería como soporte para una estructura de otro material. ${ }^{46}$ Precisamente sobre ello escribió Walter en su tratado sobre la construcción de puentes publicado en 1766, aportando varios proyectos similares al de Sala, lo que testimonia el traslado de ideas europeas hacia América. ${ }^{47}$ Por otra parte, este proyecto prueba una utilización del método científico aprendido por el ingeniero español en la Academia que permitía calcular la presión ejercida por la tabla sobre los pilares, resultando innovadora la relación entre madera y piedra entre las construcciones americanas de la época. No obstante, tras ser paralizada su ejecución por el Alcalde de Honda Antonio Ponce, el proyecto de Sala cayó en el olvido, acordando el Capítulo municipal en diciembre de 1790 realizar un nuevo puente en las inmediaciones del convento de San Francisco. ${ }^{48}$

\footnotetext{
40 BÉLIDOR, Bernard, 1729, p. 223.

41 Véase SCHRAMM, Christan, 1735.

42 GARCÍA MELERO, José Enrique, 1996, pp. 189-217.

43 Sobre el pase a Indias del ingeniero español Ignacio Sala, véase CRUZ FREIRE, Pedro, 2013.

${ }^{44}$ AGNC. Real-Hacienda-Cartas: SC. 52, 19, D. 107. "El gobernador de Cartagena, Ignacio Sala, escribe al virrey José Alfonso Pizarro". 1750, ff. 604-609.

45 AGNC. Mapoteca: SMP. 4, REF. 366a. "Plano y perfil de un puente de madera". 1750. Dicho plano ya fue reproducido por GONZÁLEZ TASCÓN, Ignacio, 1992, p. 548.

${ }^{46}$ LEUPOLD, Jacob, 1726, pp. 76-80.

47 WALTER, Gaspar, 1766, tablas V-X.

${ }^{48}$ AGNC. Mejoras-Materiales: SC. 36, 20, D.6. ff. 292-294.
} 


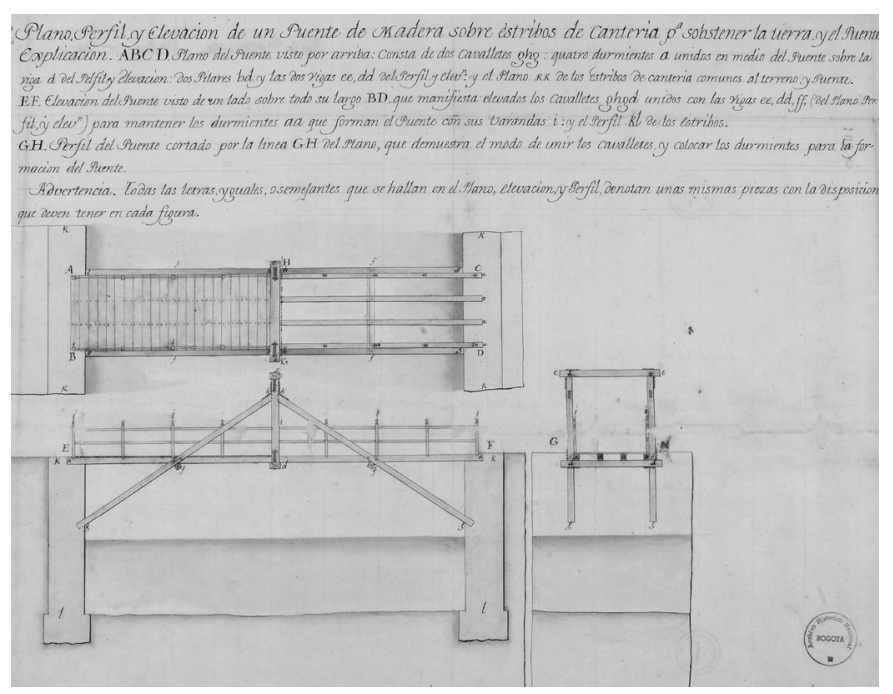

Fig. 4. Ignacio Sala. Proyecto para el puente sobre el río Gualí. 1750. Archivo General de la Nación. Colombia. Mapas y Planos, Mapoteca no 4 , ref ${ }^{3}$ 366-A.

Por último, poco antes de finalizar el siglo XVIII, el ingeniero Carlos Francisco Cabrer intervino en el llamado Puente Grande. Construido por el arquitecto jesuita Juan Bautista Coluccini en 1635 era el puente de mayor envergadura de cuantos atravesaron el río Bogotá. Sin embargo, tras sufrir algunos desperfectos generados por las continuas crecidas, el cabildo encargó a Cabrer la fabricación de una alcantarilla que corriese bajo la tabla del propio puente. A su proyecto adjuntó un plano en el que incluyó la nueva sección y planta, incorporando una empalizada bajo los pilares que reforzasen los arcos de medio punto. ${ }^{49}$ La utilización de este mecanismo permitía salvar el estado fangoso del fondo, terraplenándose el hueco resultante con carbón y piedras. Asimismo, incorporaba un sistema de drenaje, basado en una estructura de tablas rellenas de grava que permitiría evacuar el agua ante posibles inundaciones. Ello evidencia la multiplicidad de soluciones propuestas por los ingenieros militares ante los variados problemas aparecidos en las obras neogranadinas, debiendo adaptar métodos, propuestas y proyectos en una traslación de ideas enormemente enriquecedora para el contexto americano.

\section{Almacenes}

Para el equipamiento de las plazas fortificadas neogranadinas era imprescindible contar con almacenes donde guardar mercancías, pertrechos de guerra o víveres. Los ingenieros militares se ocuparon de construir algunos de estos edificios, concebidos como anexos a las fortificaciones que paralelamente erigían. En consecuencia, se localizaban a poca distancia de las murallas, proyectándose como fábricas simples, generalmente de planta rectangular que albergaban un espacio diáfano para acumular el mayor número de piezas en su interior. Esta disposición, útil y funcional, no varió durante el siglo XVIII, existiendo ligeros cambios en su mobiliario interior dependiendo del producto a almacenar.

La importancia estratégica adquirida por Cartagena de Indias durante el siglo XVIII necesitó de la construcción de varios almacenes que debían sustituir al construido en 1587, pues éste no podía albergar tan alta cantidad de munición y armas requeridas para las nuevas fortificaciones. En 1729, siendo gobernador Antonio de Salas, se aprobó la construcción de unos almacenes para la custodia de municiones, para galeones y otros navíos de guerra por el ingeniero Juan de Herrera y Sotomayor. El enclave elegido colindaba con la Aduana, la Contaduría y la Casa de Armas, agrupándose así todos los edificios destinados al almacenaje y cobro de mercancías. Además, en el barrio de Getsemaní, se aprobó en 1732 la construcción de un Real Arsenal destinado a almacenar los pertrechos de la marina. Su diseño fue realizado por el ingeniero Carlos Briones, quien elaboró diversos planos sobre el edificio, hoy no conservados, pero bien descritos en la documentación. ${ }^{50}$ Así, el Arsenal contaba con un solo piso, de planta rectangular y con espacio para albergar distintos tipos de armas, diferentes útiles de guerra y las arboladuras de los navíos. Precisamente para el almacenamiento de este elemento trazó Ignacio Sala una mejora cuando, desde Cádiz, juzgó el proyecto cartagenero. Sala propuso la apertura de un canal que introdujese agua al almacén, creando un arroyo que facilitaba la introducción de los pesados mástiles. Dicho sistema no era más que una traslación del utilizado en el arsenal gaditano de La Carraca, bien conocido por el ingeniero. ${ }^{51}$ Para su funcionamiento era necesario que el agua no subiese a mayor altura que la de su

49 AGNC. Mapoteca: SMP. 4, REF. 423-A. "Alcantarilla que se habrá de hacer en el Puente Grande", 1799.

50 AGI. Santa Fe, 938. "Explicación de la fábrica del Real Arsenal de Marina". Cartagena de Indias. 25 de agosto de 1730.

51 AGI. Santa Fe, 938. "El ingeniero director don Ignacio Sala informa sobre los planos y seis cartas del gobernador de Cartagena de Indias tocantes a las fortificaciones de aquella plaza". Cádiz. 13 de enero de 1733. El principal estudio sobre La Carraca es el realizado por BARROS CANEDA, José Ramón, 1989. 
punto de origen, necesitando alcanzar un nivel similar a lo largo del canal como recomendaba Plo y Camín en su tratado. ${ }^{52}$

Sin embargo, parece que ni la propuesta de Briones, ni la que en 1755 hizo Lorenzo de Solís Ilegaron a efectuarse, pues no consta ningún documento que así lo acredite, quedando la ciudad sin almacenes suficientes. Fue precisamente esto lo que destacó el ingeniero Antonio de Arévalo en su plan general de fortificación, pues aunque la plaza tuviese las mejores defensas, éstas nunca serían útiles si no contaban con edificios para acopiar armas y municiones. Para solucionar este problema, Arévalo propuso en 1789 la construcción de veintidós bóvedas en paralelo a la cortina de Santa Catalina, constituyendo el mejor exponente de almacenes de cuantos se construyeron. ${ }^{53}$ Su entrada se realiza a través de una galería porticada con arcos apeados en pilares, creando un espacio abierto entre la calle y el almacén que denota un sentido urbanístico del espacio por parte de Arévalo. Con ello, el ingeniero no solo se ocupaba de la defensa, sino que, además de equipar de infraestructuras a un sector de la ciudad, se preocupaba por embellecerla y dotarla de monumentalidad. La construcción de las bóvedas permitía asistir a la ciudad en caso de asedio, al poder acumular víveres suficientes como para alimentar a los habitantes. Por otro lado, su localización estratégica, lejos de la bahía interior y apartada de cualquier ataque por ese frente, imposibilitaba que los enemigos destruyesen el material conservado. Igualmente, al estar cerca de la muralla del norte, se facilitaba el tránsito de munición y armas entre los distintos baluartes que jalonaban el perímetro fortificado.

\section{Hospitales y lazaretos}

La variedad tipológica de hospitales existente en la tradición arquitectónica española tuvo su eco en lo proyectado para las ciudades americanas. Consciente de la necesidad de tratar nuevas enfermedades, la Corona promulgó una política de construcción de edificios asistenciales desde las primeras décadas del siglo XVI, advirtiendo una evolución en sus formas de acuerdo a las distintas tendencias estéticas y a los requerimientos de cada dolencia. No obstante, el desarrollo urbano alcanzado por las plazas neogranadinas durante el siglo XVIII requería de una modernización de estas infraestructuras, recayendo en los ingenieros militares la transfor-

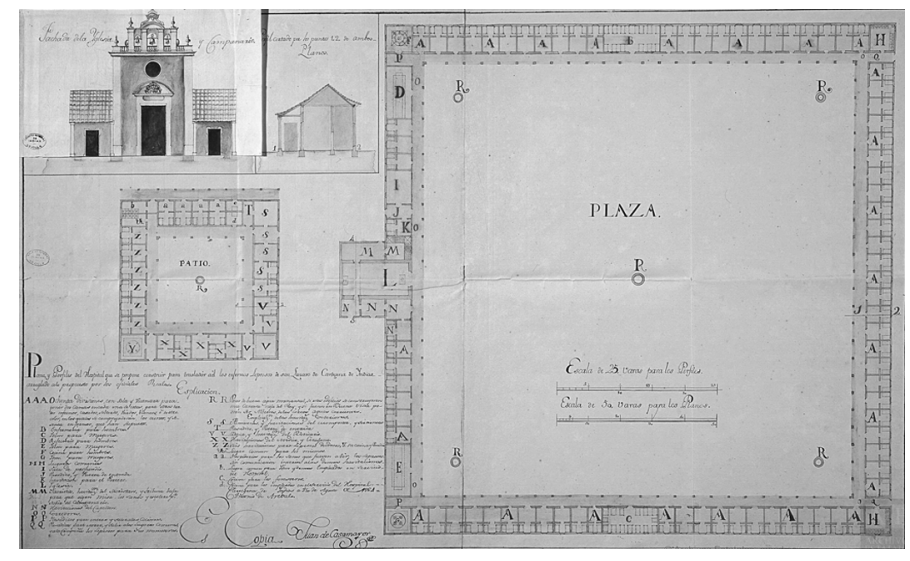

Fig. 5. Antonio de Arévalo. Proyecto para el hospital de San Lázaro de Cartagena de Indias. 1764. Archivo General de Indias. España. Mapas y Planos, MP-Panama, 248.

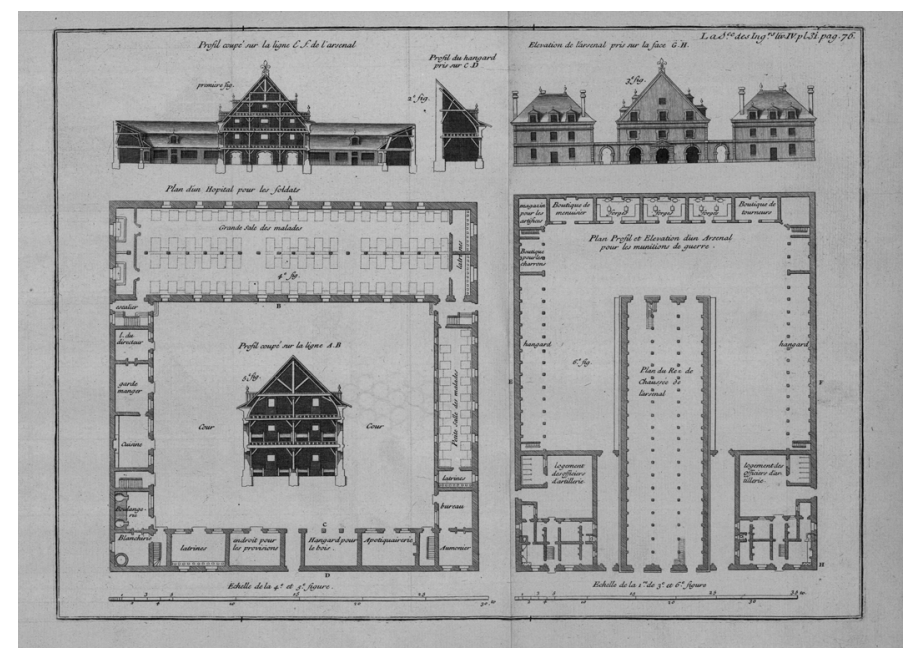

Fig. 6. Bernard Forest de Belidor. Proyecto de Hospital para soldados. La Science der Ingenieurs dans la conduite des travaux de fortification et d'architecture civile. París. 1724.

mación de algunos de sus trazados e incluso el diseño de nuevos hospitales, intuyéndose en éstos las nuevas ideas higienistas forjadas en Europa. Entre éstas, en el tratado de Juan de Esteynesser, publicado en 1712 , se advierte un minucioso análisis de las principales enfermedades, considerándose ya a la lepra como la más importante pandemia de cuantas se conocían. ${ }^{54}$ Para su cura, el jesuita aconseja-

\footnotetext{
52 PLO Y CAMÍN, Antonio, 1767, Libro III, Capítulo III.

53 MARCO DORTA, Enrique, 1988, pp. 305-308.

${ }^{54}$ ESTEYNESSER, Juan, 1712, pp. 355-358.
} 
ba, además de bañarse en el mar y comer alimentos específicos, aislar a los afectados en espacios amplios y aireados, pues ello limpiaría las heridas epidérmicas.

Todo ello era bien conocido por los ingenieros militares españoles destinados a Nueva Granada, quienes encabezaron las modificaciones de los lazaretos allí construidos. Tal fue el caso del proyectado en Caracas por iniciativa del gobernador Felipe Ricardos, tras haber advertido a la Corte en 1751 sobre los numerosos enfermos que deambulaban por las calles. En mayo del mencionado año se le encargó al ingeniero Juan de Gayangos Lascari el diseño del nuevo hospital, aprobándose su construcción por el cabildo municipal..$^{55}$ El hospicio se construyó en el barrio de "El Rosario", alejado del centro de la ciudad, lo que evitaría el contagio de la población. Lascari proyectó un patio central que permitía airear cada una de las estancias, encontrándose entre éstas una iglesia, un cementerio y una casa para el procurador.

Similar fue el proyecto concebido por Antonio de Arévalo para el nuevo Hospital de San Lázaro de Cartagena de Indias en 1764, construido en el entorno del Caño del Oro y ya desaparecido. Destruido el antiguo edificio por razones castrenses, pues entorpecía la defensa del castillo de San Felipe de Barajas, el gobernador, marqués de Sobremonte, propuso la construcción de un nuevo lazareto que cumpliese con las nuevas medidas higiénicas promulgadas por Carlos III. Para ello, Arévalo diseñó un edificio diáfano representado en el plano reproducido, formado por cuatro galerías de un solo piso en torno a un gran patio, ubicándose al centro de una de ellas la iglesia y las salas de servicio. ${ }^{56}$ Con esta tipología, similar al lazareto caraqueño pero diferente al proyectado para La Habana por Antonio de Arredondo basado en los modelos pabellonarios, se pretendía mejorar la ventilación del hospital. Arévalo adaptó la propuesta que Belidor había incluido en su tratado sobre ingeniería publicado en 1724, en el cual planteaba un diseño de hospital que por primera vez asumía las necesidades mencionadas, considerando el patio central como el eje vertebrador de todo el edificio. ${ }^{57}$ Lo propio hizo el arquitecto Alexander Rowehead para el Hospital Naval de Sto- nehouse en 1756, pionero en la incorporación de un patio entre pabellones contiguos. El modelo de Rowehead fue reproducido en varios lazaretos europeos durante el siglo XVIII, caso de los proyectados por John Howard para Marsella, por los ingenieros franceses Bruyère y Rolland en la orilla del Po o por el ingeniero español Fernández de Angulo en el hospital de Mahón. ${ }^{58}$ Todos ellos abogaban por espacios amplios que ventilasen las distintas estancias e impidiesen la propagación de la enfermedad, un modelo trasladado a América por Arévalo, buen conocedor de las teorías arquitectónicas coetáneas.

\section{Conclusiones}

Al finalizar el análisis de los principales edificios públicos que en la Nueva Granada construyeron los ingenieros militares, diferenciando sus grados de intervención, sus propuestas y la importancia de sus novedades, se reafirma lo variado de sus producciones. A pesar de que no fuese homogéneo el número de ingenieros destinados al territorio estudiado, la cantidad de proyectos abarcados entre fortificaciones y obras públicas denota una capacidad de trabajo extraordinaria. Ello también se manifiesta en el interés suscitado por la utilización de modelos y repertorios formales escogidos de la tradición europea, llevados a América mediante su adaptación a un terreno dispar, a materiales distintos y a un medio expuesto a continuos conflictos. Es evidente que los ingenieros supieron solventar todos los problemas resultantes, configurando un catálogo de obras, tan numeroso como heterogéneo, que viene a completar lo realizado en las fortificaciones neogranadinas, consideradas algunas de ellas como las más representativas de cuantas la Corona española levantó en América.

Ciertamente, la fundación en paralelo del Real Cuerpo de ingenieros y del virreinato de la Nueva Granada durante las primeras décadas del siglo XVIII permitió emprender un conjunto de reformas en las ciudades del Caribe sur resultantes del nuevo plan de aprendizaje impuesto en la Academia. El conocimiento de distintas técnicas de construcción, la formación matemática y el estudio de las ciencias empíricas solucionó los problemas de disposición urbanística de las ciudades, así como

\footnotetext{
55 AGI. "Sobre la construcción del Hospital de Caracas". Caracas, 14 de octubre de 1751. Felipe Ricardos al Marqués de la Ensenada. Signatura Caracas, 367.

${ }^{56}$ AGI. "Plano y perfil del Hospital para enfermos leprosos de San Lázaro de Cartagena de Indias". 25 de agosto de 1764. Antonio de Arévalo. Signatura MP-Panama, 248.

57 FOREST DE BELIDOR, Bernard, 1724, pp. 392-394.

58 BONASTRA, Quim, 2008, pp. 251-257.
} 
otras dificultades en la mecánica y en la distribución interna de los inmuebles. Por otro lado, el conocimiento de los tratados de arquitectura e ingeniería posibilitó la adaptación de los modelos y normas en ellos recogidos. Todo ello constituyó un corpus de obras en las que los ingenieros militares, más allá del trabajo en las fortificaciones y en la defensa del territorio, se erigieron como los responsables de los principales edificios de la administración, de la política y del gobierno virreinal.

\section{Bibliografía}

AA.VV. Puertos y fortificaciones en América y Filipinas. Madrid: Investigación Gráfica, 1985.

AA.VV. Fortificaciones del Caribe. Memoria de la reunión de expertos. Cartagena de Indias: Fas Producciones Editoriales, 1996.

AGUILAR CIVERA, Inmaculada. Puentes históricos. El patrimonio de la obra pública y los criterios y técnicas de restauración. Valencia: Fundación Demetrio Ribes y Consejería de Transporte, 2008.

AGUILAR CIVERA, Inmaculada. El discurso del ingeniero en el siglo XIX: aportaciones a la historia de las obras públicas. Madrid: Fundación Juanelo Turriano y Consellería de Infraestructuras de la Generalitat de Valencia, 2012.

AGUILAR CIVERA, Inmaculada y DOMÉNECH GARCÍA, Sergi (coords.). Fotografía y obra pública. I Workshop Internacional. Estudios interdisciplinares en la historia de la obra pública. Valencia: Conserjería de Infraestructuras, Territorio y Medio Ambiente, 2014.

ARBAIZA BLANCO-SOLER, Silvia. "La Comisión de Arquitectura y los expedientes de Ultramar en la Real Academia de Bellas Artes de San Fernando (I)". Academia. Boletín de la Real Academia de Bellas Artes de San Fernando, 2010, no 110-111, pp. 89-146.

BARROS CANEDA, José Ramón. Arquitectura y urbanismo en La Carraca durante el siglo XVIII. Sevilla: La Voz, 1989.

BÉLIDOR, Bernard Forest. La Science des Ingenieurs dans la conduite des travaux de Fortification et de Architecture civile. Libro II. Paris, 1729.

BONASTRA, Quim. "Los orígenes del lazareto pabellonario. La arquitectura cuarentenaria en el cambio del setecientos al ochocientos". Asclepio. Revista de Historia de la Medicina y de la Ciencia, 2008, vol. LX, $n^{\circ}$ 1, pp. 237-266.

BONET CORREA, Antonio. "Razón e historia de un debate teórico-profesional". En BONET CORREA, Antonio; MIRANDA, Fátima; LORENZO, Soledad, La polémica ingenieros-arquitectos en España. Siglo XIX. Madrid: Ediciones Turner, 1985, pp. 9-75.

CALDERÓN QUIJANO, José Antonio. Las fortificaciones españolas en América y Filipinas. Madrid: Mapfre, 1996.

CÁMARA MUÑOZ, Alicia. "Tiburzio Spannocchi, ingeniero mayor de los reinos de España". Espacio, tiempo y forma. Serie VII. Historia del Arte, 1988, n 1, pp. 77-90.

CANTERA MONTENEGRO, Jesús. "Aportaciones singulares de los ingenieros militares a la obra civil". Revista de Historia Militar, 2012, $\mathrm{n}^{\circ}$ Extraordinario, pp. 12-32.

CAPEL, Horacio; SÁNCHEZ; Joan Eugeni; MONCADA, Omar. De Palas a Minerva. La formación científica y la estructura institucional de los ingenieros militares en el siglo XVIII. Madrid: CSIC, 1988.
CARO, Felipe. "Arquitectura penitenciaria: desde su génesis a las nuevas tecnologías de investigación criminal". Crítica, 2011, pp. s/n.

CASTILLERO CALVO, Alfredo. Portobelo y el San Lorenzo del Chagre. Panamá: Editora Novo Art, 2017a.

CASTILLERO CALVO, Alfredo. Conquista, evangelización y resistencia. Panamá: Editora Novo Art, reed. 2017b.

CRESPO DELGADO, Daniel. "Juanelo Turriano: ingenio y fama". En CÁMARA MUÑOZ, Alicia; REVUELTA POL, Bernardo, Ingenieros del Renacimiento. Madrid: Fundación Juanelo Turriano, 2014, pp. 9-24.

CRESPO DELGADO, Daniel. "Ingeniería civil e llustración en España. Ideas e imágenes". En CÁMARA MUÑOZ, Alicia; REVUELTA POL, Bernardo (coords.), Ingeniería de la llustración. Madrid: Fundación Juanelo Turriano, 2015, pp. 35-48.

CRESPO DELGADO, Daniel. Preservar los puentes: historia de la conservación patrimonial de la ingeniería civil en España (siglos XVI-1936). Madrid: Fundación Juanelo Turriano, 2017.

CRUZ FREIRE, Pedro. "El ingeniero militar Ignacio Sala, gobernador y comandante general de Cartagena de Indias. Noticias de su pase a Indias y de su labor en las defensas de la ciudad". Laboratorio de Arte, 2013, n²5, pp. 469- 481.

CRUZ FREIRE, Pedro; LÓPEZ HERNÁNDEZ, Ignacio J. (Coords.). Ingeniería e ingenieros en la América Hispana. Sevilla: Editorial Universidad de Sevilla, 2017.

DEBAUVE, Alphonse. Manuel de l'ingenieur des ponts et chaussées. París: Dunod editeur, 1871.

ESTEYNESSER, Juan. Florilegio medicinal de todas las enfermedades. México. 1712.

FELICIANO RAMOS, Héctor. El contrabando inglés en el Caribe y el Golfo de México (1748-1778). Sevilla: Diputación Provincial, 1990.

FOREST DE BELIDOR, Bernard. La Science des Ingenieurs dans la conduite des travaux de fortification et d'architecture civile. París: Libraire de SAR, 1724.

GÁMEZ CASADO, Manuel. "La pacificación de La Guajira por el ingeniero Antonio de Arévalo. Sobre el proyecto de defensa de Sabana del Valle". Laboratorio de Arte 2016, n² 28, pp. 373-386.

GÁMEZ CASADO, Manuel. "Buscando al enemigo inglés. Expediciones de guardacostas españoles al golfo del Darién, 1767-1768". Anuario de Estudios Americanos, 2018, vol. 75, pp. 211-236.

GARCÍA MELERO, José Enrique. "Los puentes y la Comisión de Arquitectura (1786-1808)". Espacio, Tiempo y Forma, 1996, t. 9, pp. 189-217.

GONZÁLEZ TASCÓN, Ignacio. Ingeniería española en UItramar. Siglos XVI-XIX. Madrid: CEHOPU, 1992.

GUTIÉRREZ, Ramón y ESTERAS, Cristina. Territorio y fortificación: Vauban, Fernández de Medrano, Ignacio Sala y Félix Prósperi: influencia en España y América. Madrid: Ediciones Tuero, 1991.

GUTIÉRREZ, Ramón y ESTERAS, Cristina. Arquitectura y fortificación. De la llustración a la independencia americana. Madrid: Ediciones Tuero, 1993.

GUTIÉRREZ, Ramón. Fortificaciones en Iberoamérica. Madrid: Iberdrola, 2005.

KUETHE, Allan; KENNETH, Andrien. The spanish Atlantic World in the Eighteenth Century. War and the Bourbon Reforms, 1713-1796. Nueva York: Cambridge University Press, 2014.

LAORDEN RAMOS, Carlos. Obra civil en ultramar del Real Cuerpo de Ingenieros. Virreinatos de Nueva España y Nueva Granada. Tomo I. Madrid: Ministerio de Defensa, 2008. 
LAORDEN RAMOS, Carlos. "Obras civiles en América del Arma de Ingenieros". Revista de Historia Militar, 2012, n Extraordinario, pp. 137-154.

LEUPOLD, Jacob. Theatrum Pontificiale. Leipzig: Buntel, 1726.

LÓPEZ HERNÁNDEZ, Ignacio J. "El cuerpo de ingenieros militares y la Real Junta de Fomento de la Isla de Cuba. Obras públicas entre 1832 y 1854". Espacio, tiempo y forma, 2016, n 4, pp. 483-508.

LÓPEZ HERNÁNDEZ, Ignacio J. "Proceso y proyectos sobre la construcción de la Aduana de Campeche. 1778-1790". En ALBERO MUÑOZ, María del Mar; PÉREZ SÁNCHEZ, Manuel. Las artes de un espacio y un tiempo: el setecientos borbónico. Madrid: Fundación Universitaria Española, 2015, pp. 187-203.

LÓPEZ RIVERO, Raúl. Las fortificaciones de Maracaibo. Siglos XVII y XVIII. Zulia: Dirección de Cultura, 1968.

LUENGO GUTIÉRREZ, Pedro. "Cristóbal de Rojas: nuevos datos sobre su biografía y primeras obras". Archivo Español de Arte, 2018, n 362, pp. 113-126.

LUENGO MUÑOZ, Manuel. "Génesis de las expediciones militares al Darién en 1785-6". Anuario de Estudios Américanos, 1961, vol. 18, pp. 333-416.

MARCHI, Francesco. Architettura militari: libri tre, nelli quali si descrivono li veri modi del fortificare, che si usa á tempi moderni. Brescia, 1603.

MARCO DORTA, Enrique. Cartagena de Indias. Puerto y plaza fuerte. Bogotá: Fondo Cultural Cafetero, 1988.

MORALES, Alfredo J. "La portada del convento de Santo Domingo en Sanlúcar de Barrameda, obra de Cristóbal de Rojas". Revista de Arte Sevillano, 1982, n 1, pp. 17-20.

MORALES, Alfredo J. "América y los ingenieros de Carlos III". En ALMANCHA NUNEEZ-HERRADOR, Esther, MARTíNEZ BURGOS, Palma y SAINZ MAGAÑA, Elena (eds.). El Greco en su IV Centenario: Patrimonio Hispánico y diálogo cultural. Toledo: Ediciones de la Universidad de Castilla-La Mancha, 2016, pp. 67-78.

NAVARRO GARCÍA, Luís. Hispanoamérica en el siglo XVIII. Sevilla: Editorial Universidad de Sevilla, 1975.
PÉREZ SINDREU, Francisco de Paula. "Alonso Turrillo de Yebra. Fundador y primer tesorero de las Casas de la Moneda de Cartagena y Santa Fe, en el Nuevo Reino de Granada. Primeras labores (1620-1634)". Acta numismática, 1995, n² 25, pp. 143-156.

PLO Y CAMÍN, Antonio. El arquitecto práctico, civil, militar y agrimensor. Madrid: Imprenta Pantaleón Aznar, 1767.

POLO ACUÑA, José. "Antonio de Arévalo y la frontera de la península de La Guajira. 1770-1776". Taller de Historia, 2001, vol. 1, pp. 213-250.

REDONDO CANTERA, María José; ARAMBURU-ZABALA Miguel Ángel. "La construcción de puentes en el siglo XVIII: innovación y tradición". En AA.VV. Actas del I Congreso Nacional de Historia de la Construcción. Madrid: CEHOPU, 1996, pp. 435-443.

SAMBRICIO, Carlos. "La ordenación del territorio como utopía real en la España ilustrada". En AA.VV. El Canal de Castilla. Valladolid: Junta de Castilla y León, 1986, pp. 13-38.

SCHRAMM, Christan. Historia de los puentes más extraños. Leipzig: 1735.

SERRANO ÁLVAREZ, José Manuel. Fortificaciones y tropa. El gasto militar en Tierra Firme. 1700-1788. SeviIla: Diputación Provincial, 2003.

SERRANO ÁLVAREZ, José Manuel. "El éxito de la escasez. La defensa de Cartagena de Indias en 1741". Vegueta, 2006, vol. XIV, pp. 359-383.

WALTER, Gaspar. Brücken-Bau, oder Anwrisung, wie allerley Arte von Bruecken. Ausburgo, 1766.

ZAPATERO, Juan Manuel. Historia de las fortificaciones de Puerto Cabello. Caracas: Banco Central de Venezuela, 1977.

ZAPATERO, Juan Manuel. Historia de las fortificaciones de Cartagena de Indias. Madrid: Ediciones Cultura Hispánica, 1979.

ZAPATERO, Juan Manuel. Historia de las fortalezas de Santa Marta y estudio asesor para su restauración. Bogotá: Academia Colombiana de Historia, 1980. 